\title{
The effect of standardised submaximal work load on intraocular pressure
}

\author{
AMIRAM SHAPIRO, YEHUDA SHOENFELD,* AND YAIR SHAPIRO* \\ From the Hadassah University Hospital, Jerusalem, Isratl, and the ${ }^{*}$ Heller Institute of Medical Research, \\ Chaim Sheba Medical Center, Tel-Hashomer and Sackler School of Medicine, Tel Aviv University, \\ Tel Aviv, Israel
}

SUMMARY A relatively small decrease in intraocular pressure secondary to submaximal work can be demonstrated when factors other than the work load itself are eliminated-diurnal variation, body position, and the effect of repeated examinations. A feedback mechanism that causes a return of IOP towards its normal value after work-induced decreases is postulated.

Decreases of intraocular pressure (IOP) related secondarily to physical exercise, have been reported (Leighton and Phillips, 1970; Marcus et al., 1970a; Myers, 1974). It has been shown that this effect is inversely proportional to the work load (Lempter and Cooper, 1967; Kieler et al., 1975). Other authors have found that IOP varies diurnally (Drance, 1960), changes with body position (Krieglestein and Langham, 1975), and the numerical value may be altered by the measuring technique itself (Duke-Elder, 1969).

The purpose of this study was to determine the effect of continuous and increasingly difficult periods of standardised submaximal work on intraocular pressure. The effect of all the previously mentioned factors were taken into account in analysing the data.

\section{Subjects and methods}

Eight healthy male volunteers aged 29 to 36 years (mean 31.4 years, SD 2.2 years) were studied. Their mean weight and height were $66.5 \mathrm{~kg} \pm 10.7$ and $171.5 \mathrm{~cm} \pm 8.8$, respectively. All subjects underwent an ophthalmological examination which included an ophthalmoscopic examination, anterior segment biomicroscopy, refractive error determination, and repeated applanation intraocular pressure determinations.

Six subjects were found to be emmetropic; one was myopic, -6.00 dioptres in both eyes; and one had -3.00 dioptres in the right eye and 5.50 dioptres

Address for reprints: Dr Amiram Shapiro, Department of Ophthalmology, Hadassah University Hospital, Jerusalem, Israel in the left eye. No other ocular abnormality was found.

Before beginning this study none of the subjects had participated in a regular bicycle riding programme. Prediction of each subject's maximal oxygen uptake $\left(\mathrm{VO}_{2}\right.$ max) was assessed according to Astrand and Rodahl (1970). Mean $\mathrm{VO}_{2}$ max was $41.8 \mathrm{ml} / \mathrm{kg}$. $\mathrm{min} \pm 6.2$ and ranged from 36 to $50 \mathrm{ml} /$ $\mathrm{kg}$.min. The volunteers thus all fell into the range of individuals having average physical fitness.

Each person was tested 4 times by different exercise tests at 1-week intervals. Each session began at 9 a.m., 2 hours after breakfast. The laboratory temperature was $20^{\circ} \mathrm{C}$. Four different test conditions were studied: Condition A, sitting upright on the bicycle ergometer for 1 hour; condition $B$, pedalling continuously at a rate of $50 \mathrm{cycles} / \mathrm{min}$ for 1 hour at a constant work load of 50 watts; condition $C$, an initial period of rest of 15 minutes followed at 9.15, 9.35, and 9.55 a.m. by a 5-minute period of pedalling at a rate of 50 cycles/min at light loads of 25,50 , and 75 watts, respectively (between active periods the subjects rested while seated on the ergometers); condition $D$, similar to condition $C$, but with moderate work loads of 100,125 , and 150 watts for the exercise period.

The intraocular pressure was measured in the last 30 seconds of the 19th, 39th, and 59th minutes under all conditions with a Drager applanation tonometer (Moller-Weder, West Germany) (Drager, 1967), under topical anaesthesia (benoxinate hydrochloride $0.2 \%$ and fluororescein sodium $0.25 \%$ ). All measurements were performed by the same examiner, first on the right eye and then on the left eye.

Different orders of the conditions were used in 
Table 1 Intraocular pressure for submaximal steady state work (mean and standard deviation, range, and significance of change compared to condition A). NS = not significant

\begin{tabular}{|c|c|c|c|c|c|c|}
\hline & Condition D & Condition $\mathbf{C}$ & Condition B & Condition A & Time (h) & \\
\hline Mean \pm SD & $11 \cdot 5 \pm 1 \cdot 7$ & $15 \cdot 0 \pm 2 \cdot 2$ & $15 \cdot 0 \pm 3 \cdot 1$ & $17 \cdot 3 \pm 3 \cdot 5$ & 0920 & Right \\
\hline Range & $10-15$ & $10-19$ & $10-18$ & $12-24$ & & eye \\
\hline $\mathbf{P}<$ & 0.001 & 0.001 & 0.005 & & & \\
\hline Mean $>$ SD & $13 \cdot 8 \pm 4 \cdot 2$ & $13 \cdot 6 \pm 2 \cdot 5$ & $14 \cdot 0 \pm 4 \cdot 5$ & $15 \cdot 5 \pm 3 \cdot 5$ & 0940 & \\
\hline Range & $8-22$ & $10-17$ & $8-18$ & $10-20$ & & \\
\hline $\mathbf{P}<$ & NS & 0.025 & NS & & & \\
\hline Mean \pm SD & $12 \cdot 3 \pm 2 \cdot 6$ & $13 \cdot 7 \pm 2 \cdot 8$ & $16 \cdot 1 \pm 3 \cdot 2$ & $15 \cdot 8 \pm 3.0$ & 1000 & \\
\hline Range & $9-16$ & $11-18$ & $11-21$ & $10-19$ & & \\
\hline $\mathbf{P}<$ & 0.025 & 0.05 & NS & & & \\
\hline Mean \pm SD & $13 \pm 3.6$ & $15 \cdot 6 \pm 3.0$ & $16 \cdot 1 \pm 4 \cdot 2$ & $16 \cdot 5 \pm 4 \cdot 2$ & 0920 & Left \\
\hline Range & $9-19$ & 11-19 & $10-24$ & $9-22$ & & eye \\
\hline $\mathbf{P}<$ & 0.05 & 0.01 & 0.025 & & & \\
\hline Mean $\pm S D$ & $11 \cdot 6 \pm 3 \cdot 5$ & $14 \cdot 3 \pm 4 \cdot 0$ & $15 \cdot 7 \pm 3 \cdot 5$ & $15 \cdot 8 \pm 4 \cdot 2$ & 0940 & \\
\hline Range & $7-17$ & $9-21$ & $12-21$ & $10-21$ & & \\
\hline $\mathbf{P}<$ & 0.005 & 0.025 & NS & & & \\
\hline Mean \pm SD & $12 \cdot 5 \pm 3 \cdot 5$ & $12 \cdot 1 \pm 3 \cdot 3$ & $18 \cdot 4 \pm 2 \cdot 7$ & $13 \cdot 7 \pm 3 \cdot 8$ & 1000 & \\
\hline Range & $6-17$ & $8-16$ & $15-23$ & $9-20$ & & \\
\hline $\mathbf{P}<$ & 0.05 & 0.025 & 0.010 & & & \\
\hline
\end{tabular}

every 2 subjects (A, B, C, D; B, C, D, A; C, D, A, B; D, A, B, C). Data were evaluated by the paired Student $t$ test when appropriate.

\section{Results}

Intraocular pressure (mean, standard deviation, and range) for the experimental conditions are listed in Table 1. The results of the first 40 minutes of continuous submaximal work load of 50 watts (condition $B$ ) show a slight decrease in IOP, but after 60 minutes of exercise the IOP rises to above the IOP measured at a similar period of rest (condition $A$ ). Stepwise increases in work load (conditions $C$ and $D$ ) cause a decrease of IOP when compared to rest (condition A). There does not appear to be any correlation between further decrease in intraocular pressure and increasing work load $(P<0.05)$.

\section{Discussion}

In the present study riding a bicycle ergometer was chosen for two reasons: the feasibility of examining the subjects' IOP during exercise, and because this form of activity is well accepted as a means for calibrated levels of physical exercise (Astrand and Rodahl, 1970).
Only a small decrease of IOP was found during submaximal work loads (conditions $B, C$, and $D$ ). For continuous pedalling at a work load of 50 watts (condition $B$ ) a fall was noted during the first 40 minutes, but a relative increase in IOP was noted at 60 minutes. No significant decreases of IOP were recorded with a stepwise increase of work load.

Previous investigations have reported more remarkable decreases of IOP during work (Leighton and Phillips, 1970; Marcus et al., 1970a; Meyers, 1974) and larger drops of IOP with increases of work load (Lempter and Cooper, 1967; Kieler et al., 1975). In some of these reports IOP changes were taken as the difference of measurements before and after work (Lempter and Cooper, 1967; Marcus et al., 1971a; Meyers, 1974). This method does not account for either diurnal variation or the effect of repeated measurements. Diurnal changes can occur over as short a time as $\mathbf{2 0}$ minutes and may be as great as the changes noted during exercise (Henkind, 1973). In addition, repeated tonometric measurements may themselves lower the IOP (Stocker, 1958). In some of these studies the IOP was measured with the body in a different position from that in which the exercise was carried out (Lempter and Cooper, 1967; Leighton and Phillips, 1970; Kieler et al., 1975). It is well known that a change in body position can also effect a change in IOP (Kriegles- 
tein and Langham, 1975). In some experiments the IOP was measured with a Schiotz tonometer (Lempter and Cooper, 1967; Kieler et al., 1975), which is a less precise instrument than the applanation tonometer (Duke-Elder, 1969).

In the present study the change of IOP during work was the difference between the pressure measured at the end of steady state work and that for the same hour of the day and laboratory environment at rest. All measurements were made with an applanation tonometer with the subjects seated on the ergometer. By this method we attempted to exclude all the changes of IOP due to diurnal variation, body position, and repeated measurements with applanation tonometer. The attention paid to these factors in the present study explains the discrepancy between our results and the results of previous studies.

The physiological mechanisms responsible for the decrease of IOP at work are not clear (Kieler et al., 1975). The decrease in IOP has been attributed to a decrease of blood $\mathrm{pH}$ and an increase in plasma osmolarity (Marcus et al., 1970b). There may be a negative feedback mechanism causing a compensatory rise in IOP after the decrease induced by physical work. A similar feedback mechanism has been postulated to explain the increase of IOP that follows the initial pressure-lowering effects of ocular massage or hyperosmolar intravenous infusions (Robbins, 1971). In the continuous steady-state submaximal work (condition $B$ ) this feedback mechanism returned IOP towards its normal level after 40 minutes, with rebound seen as the IOP rises above its normal value at 60 minutes. Stepwise increases of work failed to show stepwise decreases of IOP due to the equalisation by the feedback mechanism.

It would appear from the data reported that two opposing mechanisms are affecting the intraocular pressure during a work load: (1) a fall secondary to physiological changes produced during exercise, and (2) a negative feedback attempting to stabilise the change. The result is that in the submaximal work range there is a small change in IOP.

\section{References}

Astrand, P. O., and Rodahl, K. (1970). Evaluation of physical work capacity on the basis of tests. In Textbook of Work Physiology, pp. 341-364. McGraw-Hill: New York.

Drager, J. (1967). Principle of clinical application of a probable applanation tonometer. Investigative Ophthalmology, 6, 132-134.

Drance, S. M. (1960). The significance of the diurnal tension variations in normal and glaucomatous eyes. Archives of Ophthalmology, 64, 494-501.

Duke-Elder, S. (1969). Diseases of the lens and vitreous glaucoma and hypotony. In System of Ophthalmology, Vol. II, pp. 455-456. Henry Kimpton: London.

Henkind, P., Leitman, M., and Weitzman, E. (1973). The diurnal curve in man: new observations. Investigative Ophthalmology, 12, 705-707.

Kieler, R. A., Teraslinna, P., Rowe, D. G., and Jackson, J. (1975). Standardized aerobic and anaerobic exercise: differential effects on intraocular tension, blood $\mathrm{pH}$, and lactate. Investigative Ophthalmology, 14, 782-785.

Krieglestein, G. K., and Langham, M. E. (1975). Influence of body position on the intraocular pressure of normal and glaucomatous eyes. Ophthalmologica, 171, 132-145.

Leighton, D. A., and Phillips, C. I. (1970). Effect of moderate exercise on the ocular tension. British Journal of Ophthalmology, 54, 599-605.

Lempter, P., and Cooper, K. (1967). The effect of exercise on intraocular pressure. American Journal of Ophthalmology, 63, 1673-1676.

Marcus, D. F., Krupin, T., Podos, S. M., and Becker, B. (1970a). The effect of exercise on intraocular pressure. I. Human beings. Investigative Ophthalmology, 9, 749-752.

Marcus, D. F., Krupin, T., Podos, S. M., and Becker, B. (1970b). The effect of exercise on intraocular pressure. II. Rabbits. Investigative Ophthalmology, 9, 753-757.

Meyers, K. J. (1974). The effect of aerobic exercise on intraocular pressure. Investigative Ophthalmology, 13, 74-76.

Robbins, R. M., Obstbaum, S. A., and Galin, M. A. (1971). Intraocular pressure rebound. British Journal of Ophthalmology, 55, 177-182.

Stocker, F. W. (1958). On changes in intraocular tension with application of tonometer. American Journal of Ophthalmology, 45, 192-195. 